\title{
Catchment grouping and regional calibration for predictions in ungauged basins
}

\author{
B. Wang ${ }^{\text {a }}$ J. Vaze ${ }^{\text {a }}, \underline{\text { Y.Q. Zhang }}{ }^{\text {a }}$ and J. Teng ${ }^{\text {a }}$ \\ ${ }^{a}$ CSIRO Water for a Healthy Country National Research Flagship, CSIRO Land and Water, GPO BOX \\ 1666, Canberra ACT 2601, Australia \\ Email: Bill.Wang@,csiro.au
}

\begin{abstract}
Runoff prediction in ungauged regions remains a challenging task in hydrology (Sivapalan et al. 2003). The process of finding suitable parameter values to model runoff in ungauged catchments, by inferring and learning from model calibrations in gauged catchments, is generally referred to as 'regionalisation'. An increasing number of studies now use a regional calibration approach (Vogel 2005; Vaze et al. 2011a; 2013). The regional calibration finds one set of parameter values to represent the entire 'hydrologically similar' region rather than considering each catchment independently. In the regional calibration, the model parameters are optimised to produce an overall best simulation for all the gauged catchments within the region. Vaze et al. (2011a) suggested that the regional calibration has capability to accommodate extra local information by, e.g., using different sets of parameters to represent catchments with different vegetation or land use types across the target region. Vaze et al. (2013) also showed that the regional calibration approach has an advantage as it can incorporate information from new data sources, like remotely sensed vegetation, evapotranspiration and soil moisture, to improve model characterisation, reanalysis and predictions.
\end{abstract}

While applying a regional calibration to a large region such as south-eastern Australia, all catchments cannot be assumed to have similar hydrological behaviour, and hence a sub-grouping approach based on differences in physical catchment characteristics is required. This can be facilitated by using remote sensing data which provides a complete coverage of a range of catchment characteristics. There are many catchment characteristics that have been used in past studies to measure the hydrologic similarities between catchments for model regionalisation (Oudin et al. 2008; Zhang and Chiew, 2009). But there still remains a question about which catchment characteristics are more informative to measure the hydrological similarity for hydrological response in a specified region.

This study attempts to answer this question by undertaking modeling experiments by sub-grouping catchments based on three physical catchment and climate characteristics - the fraction of vegetation coverage (fPAR), aridity index (AI) and rainfall distribution over seasons (Seasonality). The hydrological model is regionally calibrated for each of the sub-groups and the calibrated model parameters are used to simulate runoff over different independent periods (model validation). The results are compared with those obtained from using sub-groups of randomly selected catchments. The results have also been compared against classic regionalisation based on spatial proximity, where all the 196 catchments are calibrated individually and the calibrated parameter set from the geographically closest catchment is used to simulate streamflow for 'ungauged' catchments. The experiments are carried out using data from 196 unregulated and unimpaired medium sized catchments $\left(50-2000 \mathrm{~km}^{2}\right.$ ) (Vaze et al., 2010) across south-eastern Australia for the period 2000-2008. The hydrological model used in this study is the 4-parameter GR4J Model (Perrin et al. 2003).

The results show that the classic local calibration and validation approach perform best, and the regional calibration against the whole catchment set (only one parameter set for all catchments) gives the worst results. The results also show that daily runoff predictions from the catchment characteristics-based subgrouping approaches perform substantially better than that from random sub-grouping. The results also indicate that predictions from sub-grouping based on both aridity index and the seasonal rainfall distribution are able to offer comparable performance to local regionalisation based on spatial proximity. Although the standards for sub-grouping and the number of sub-groups may be subjective, the results suggest that regional calibration with catchments sub-grouping based on catchment physical properties has potential to improve hydrological predictions over large regions.

Keywords: Rainfall-runoff modelling, regional calibration, regionalization, catchment characteristics 


\section{INTRODUCTION}

The process of estimating hydrological model parameters for catchments with few valid streamflow data or even without streamflow data based on calibrated parameters of gauged catchments is generally referred to as 'regionalisation'. Regionalisation remains one of the most challenging tasks in hydrology (Sivapalan et al. 2003).

There are three widely-used regionalisation approaches based on classic (local) calibration: regionalisation based on regression, regionalisation based on spatial proximity and regionalisation based on physical similarity. In the early days, the regression-based regionalisation approach was the most common method. But many recent studies using large data sets indicate that the spatial proximity approach normally provides better results than the regression-based approach. After comparing different regionalisation methods using data for 308 Austrian catchments, Merz and Bloschl (2004) concluded that spatial proximity is more informative for regionalisation than catchment attributes, which is due to the uncertainty of calibrated model parameters. Oudin et al. (2008) also reported that spatial proximity offers the best regionalisation solution after comparing the above three regionalisation methods on 913 French catchments. Zhang and Chiew (2009) found that spatial proximity outperforms physical similarity for predicting daily runoff for 240 south-eastern Australian catchments. The regression-based regionalisation is also argued against because it has problems associated with equifinality (Bardossy, 2007; Beven and Freer, 2001), i.e. similar model performance can be given by vastly different sets of parameter values.

Over the past decade, an increasing number of studies on regional calibration approaches have been reported (Vogel 2005; Parajka et al. 2007; Vaze et al. 2011b). Unlike the classic (local) calibration approach which calibrates a hydrological model against only one donor catchment, the regional calibration approach optimise hydrological model parameters for a group of catchments with similar physical or climate characteristics. As the regional calibration approach makes use of all the information across the hydrologically similar region, it has the potential to provide more meaningful a-priori parameter values that can reduce uncertainty of calibrated model parameters. Vaze et al. (2011a) suggested that the regional calibration has the capability to accommodate extra local information by, e.g., using different sets of parameters to represent catchments with different vegetation or land use types across the target region. Vaze et al. (2013) also showed that the regional calibration approach has an advantage of incorporating information from new data sources, like remotely sensed vegetation, evapotranspiration and soil moisture, to improve model characterisation, reanalyses and predictions.

While applying a regional calibration to a large region such as south-eastern Australia, all catchments cannot be assumed to have similar hydrological behaviour, and hence a sub-grouping approach based on differences in physical catchment characteristics is required. This can be facilitated by using remote sensing data which provides a complete coverage of a range of catchment characteristics. There are many catchment characteristics that have been used in past studies to measure the hydrologic similarities between catchments for model regionalisation (Oudin et al. 2008). But there still remains a question about which catchment characteristics are more informative to measure the hydrological similarity for hydrological response in a specified region.

Bloschl 2005 indicated that some measurable catchment characteristics that are used in the regionalisation relationships may have low predictive power for catchment response. Vaze et al. (2011a), based on an analysis of 10 catchments in close spatial proximity with similar climate characteristics, showed that the fraction of forest coverage is quite informative for improving the regionalisation performance with regional calibration. Merz et al. (2006) suggest that the results and conclusions based on different catchment descriptors can be quite different.

In an attempt to answer the above question, this study examines sub-grouping 196 catchments based on three physical catchment and climate characteristics - the fraction of vegetation coverage (fPAR), aridity index (AI) and rainfall distribution over seasons (Seasonality). The GR4J hydrological model (Perrin et al. 2003) is regionally calibrated for each of the sub-groups and the calibrated model parameters are used to simulate runoff over different independent periods (model verification). The results are compared with those obtained from using sub-groups of randomly selected catchments. The results have also been compared against classic regionalisation method based on spatial proximity, where all the 196 catchments are calibrated individually and the calibrated parameter set from the geographically closest catchment is used to simulate streamflow for 'ungauged' catchments. 


\section{STUDY AREA AND DATA}

The 196 study catchments are located in south-eastern Australia and the catchment area vary between $50 \mathrm{~km}^{2}$ and $2000 \mathrm{~km}^{2}$ (Figure 1). All the study catchments are largely unregulated with no major storages or irrigation schemes.


Figure 1. Study area and location of the 196 catchments across south-eastern Australia

The fraction of vegetation coverage in these catchments was calculated from the $0.05^{\circ}(\sim 5 \mathrm{~km} \times 5 \mathrm{~km})$ dataset of the fraction of Photosynthetically Active Radiation absorbed by vegetation (fPAR), derived from the Advanced Very High Resolution Radiometer (AVHRR) (Donohue et al. 2008). This study used the mean annual persistent fPAR data for 2006, and the percentage of deep-rooted vegetation (i.e. forests) varied from $12 \%$ to $94 \%$.

The aridity index in these catchments varies from 0.68 for temperate region near the coast to 3.30 for arid inland areas towards the north-west and west.

The climate data used in this study are from the SILO Data Drill (http://www.longpaddock.qld.gov.au/silo; Jeffrey et al. 2001) which provides surfaces of daily climate data for $0.05^{\circ}$ grids $(\sim 5 \mathrm{~km} \mathrm{x} 5 \mathrm{~km})$ across Australia, interpolated from station measurements made by the Australian Bureau of Meteorology.

\section{MODELLING EXPERIMENTS}

The four-parameter conceptual daily rainfall-runoff model - GR4J - was used in this study. GR4J is a simple lumped continuous daily rainfall-runoff model (Perrin et al. 2003). The GR4J model has been widely used in Australia for predicting runoff in gauged or ungauged catchments. Vaze et al. (2010) reported that, compared to the other four rainfall-runoff models (SIMHYD, AWBM, SMARG, IHACRES), GR4J and Sacramento have similar or better performance both in calibration and nearest-neighbor regionalisation for 232 catchments across south-eastern Australia.

For all modelling experiments, each of the 196 catchments was calibrated using 2000-2005 data and the simulations were carried out for 2006-2008. As the regional calibration was undertaken for each of the subgroup of catchments and a single set of parameter values were optimized to provide the best possible calibration results for all the catchments together, individual catchments with the sub-group can be considered more as 'ungauged' as removing each of them one at a time from the calibration sub-group will not have much impact on the final calibrated parameter values. Six separate sets of calibration experiments were undertaken in this study:

- All: Calibrate all 196 catchments together, i.e. only one parameter set was optimised in the calibration and used for the simulation; 
- Random: Randomly split the catchments into three equal sub-groups, and each sub-group was calibrated separately;

- $\quad$ PPAR: the catchments were split into three sub-groups based on the fPAR values: 39 catchments with fPAR value $<0.34,96$ catchments with $\mathrm{PPAR}$ value of $0.34-0.66$, and 61 catchments with $\mathrm{PAR}>0.66$;

- Aridity: the catchments were split into three sub-groups based on their aridity index: 61 catchments with aridity index $<1.2,83$ catchments with aridity index of 1.2-1.7, and 52 catchments with aridity index $>$ 1.7 ;

- Seasonality: the catchments were split into three sub-groups by the percentage of annual rainfall occurring in the summer half year (October - March): 94 winter rainfall dominated catchments with the percentage value $<0.43,68$ catchments with the percentage value of $0.43-0.57$, and 34 summer rainfall dominated catchments with the percentage value $>0.57$;

- Individual: All catchments were calibrated individually for each the 196 catchments.

For regional calibration, each sub-group was calibrated separately, i.e. one set of parameters is optimized for each sub-group. The Shuffled Complex Evolution global optimisation method (Duan et al., 1993), with multiple starting parameter sets was used to optimize the model parameters. A two year warm-up period was used for all calibration experiments. In both regional and individual calibration experiments, the model parameters are optimised to maximise a NSE-Bias objective function:

$$
\mathrm{OBJ}=\mathrm{NSE}-5|\ln (1+\mathrm{Bias})|^{2.5}
$$

The NSE-Bias objective function is a weighted combination of daily NSE (Nash and Sutcliffe 1970) and a logarithmic function of Bias (Viney et al., 2009), effectively maximising the NSE to provide the best fit between modelled and observed daily runoffs, and at the same time ensuring that the modelled and observed mean annual runoffs are similar.

The prediction performance of the calibrated model was then assessed by comparing the simulated runoff for 2006-2008 with the observed runoff. For the nearest neighbour regionalisation, each of the 196 catchments was calibrated separately using 2000-2005 data. To assess model prediction in "ungauged catchments", each of the 196 catchments is considered "ungauged" and the optimised parameter values from the nearest calibrated catchment was used to predict the 2000-2005 runoff and 2006-2008 runoff.

\section{RESULTS AND DISCUSSION}

\subsection{Calibration results}

Calibration NSE 2000-2005

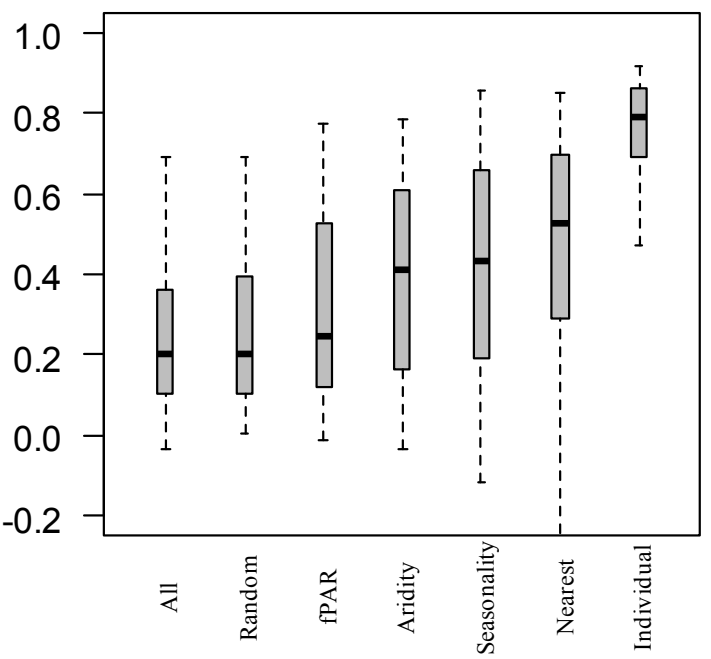

Absolute Bias 2000-2005

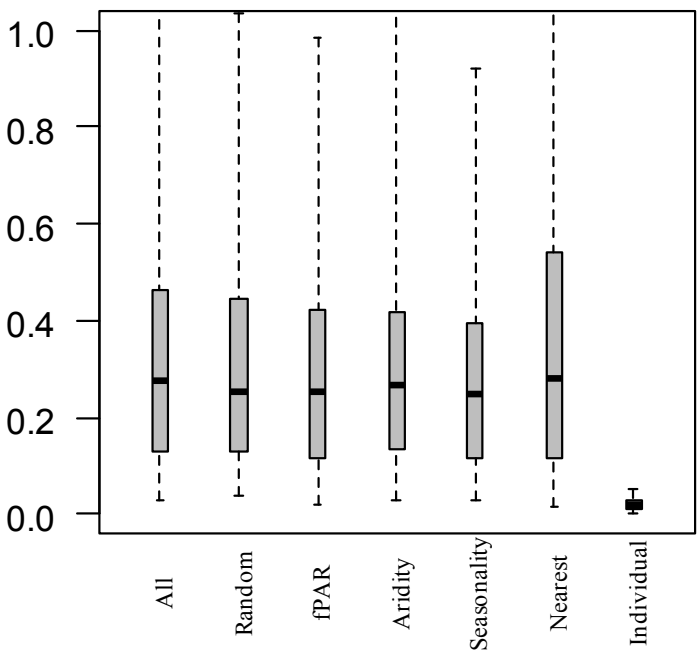

Figure 2. Comparison of calibration NSE and Bias for different calibration approaches. The boxes represent the $25^{\text {th }}$ and $75^{\text {th }}$ percentiles, the median is marked with a thick horizontal line, and the whiskers represent the $5^{\text {th }}$ and $95^{\text {th }}$ percentiles. 
The results (Figure 2) show that individual calibration (Individual) performs best for both NSE and absolute Bias with median values of 0.79 and 0.02 respectively. This is to be expected, as with individual calibration, the model parameters are optimised for each individual catchment and we have a total of 196 calibrated parameter sets whereas only one or three parameter sets are calibrated in regional calibration. The calibration results for 'All' and 'Random' are effectively the same indicating that randomly sub-grouping catchments in smaller groups provide little improvement over calibrating them all together. Regional calibration on three sub-groups based on 'fPAR' provides some improvement over 'All' or 'Random' with an improvement in median NSE of about 0.05 . The regional calibration results for the three sub-groups based on 'Aridity' improve the results further with a median NSE of 0.41 . The best regional calibration results are for the three sub-groups based on rainfall 'Seasonality' with a median calibration NSE of 0.44 . The 'Nearest' neighbor regionalisation approach provides a median NSE of 0.52 but it has a slightly higher bias (both median and the range) compared to the other approaches. All the regional calibration experiments have a median bias of about 0.26 .

\subsection{Regionalisation results}

Figure 3 summarizes the regionalisation NSE and absolute Bias results for all the calibration experiments for 2006-2008. As expected, the regionalisation results are substantially poorer than the corresponding calibration results. The individual calibration 'Individual' approach where the parameter set calibrated for each catchment for 2000-2005 is used to simulate runoff for 2006-2008 performs the best with a median NSE of 0.44 and median bias of 0.31 . This is partly because we are undertaking a split-sample analysis rather than real regionalisation where the parameters are transferred from one catchment to another. Similar to the calibration results, the regionalisation results for 'All' and 'Random' are the poorest with a median NSE of 0.11 and 0.14 respectively. The regionalisation NSE for the 'fPAR' approach is slightly better than the first two approaches. The best regionalisation NSE results amongst the regional calibration approachs is for the sub-grouping based on 'Aridity' with a median NSE value of 0.28 . The regionalisation NSE for the subgrouping based on rainfall 'Seasonality'are slightly poorer with a median NSE of 0.25 . But this approach provides the smallest bias amongst all the regional calibration approaches (median 0.36). The 'Nearest' neighbor regionalisation approach provides a median regionalisation NSE of 0.29 but it has the highest bias (median 0.50).

The regionalisation results for all the modelling experiments suggest that the sub-grouping based on aridity index and rainfall seasonality can generally improve the model performance over an independent period, whereas just randomly sub-grouping catchments into smaller groups provide little to no improvement over using all catchments together. The regionalisation results also show that the regional calibration based on sub-grouping for 'Aridity' and rainfall 'Seasonality' with three sets of calibrated parameter values can provide comparable results to those from the classical spatial proximity approach with 196 sets of calibrated parameter sets.
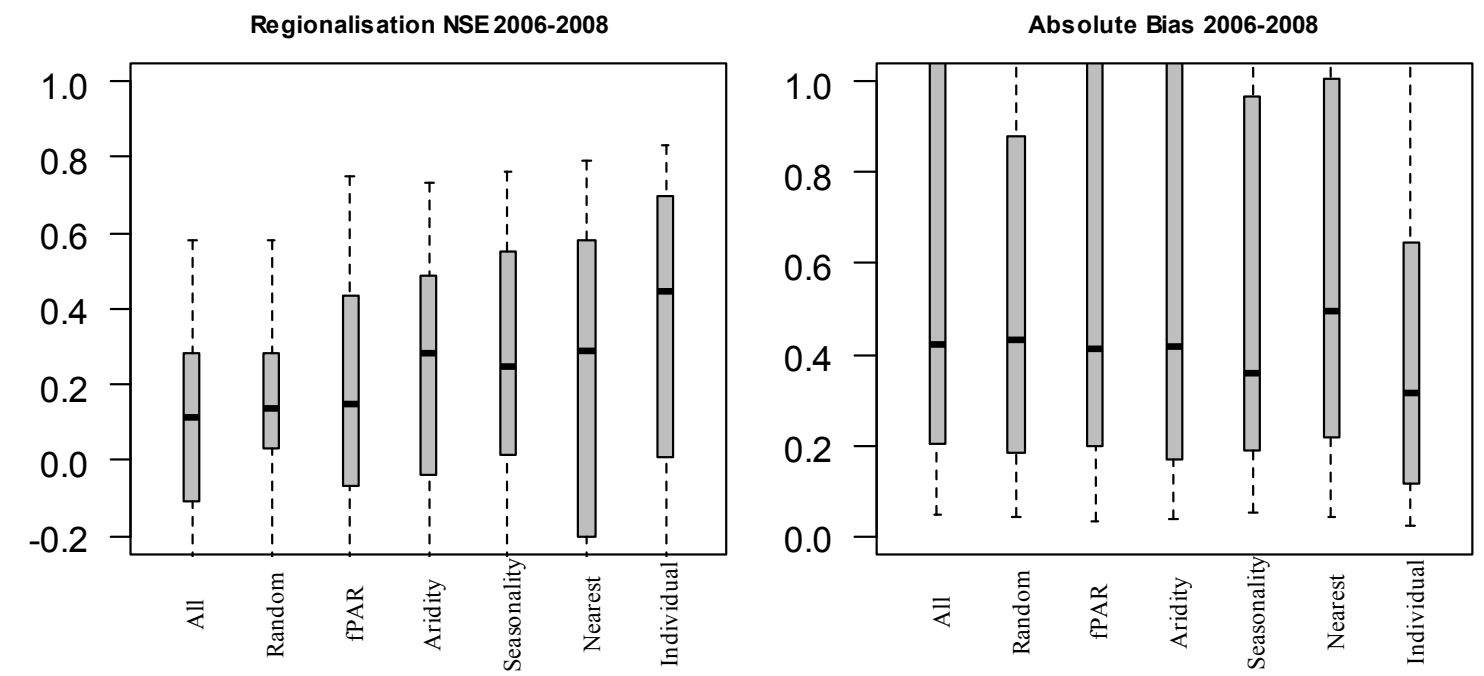

Figure 3. Comparison of regionalisation NSE and Bias for different calibration approaches. The boxes represent the $25^{\text {th }}$ and $75^{\text {th }}$ percentiles, the median is marked with a thick horizontal line, and the whiskers represent the $5^{\text {th }}$ and $95^{\text {th }}$ percentiles. 


\section{SUMMARY}

This study investigates the relative performance of different regional calibration approaches using data from 196 catchments across south-eastern Australia. The catchments are sub-grouped based on three physical catchment and climate characteristics - the fraction of vegetation coverage (fPAR), aridity index (AI) and rainfall distribution over seasons (Seasonality). The GR4J hydrological model is regionally calibrated for each of the sub-groups and the calibrated model parameters are used to simulate runoff over different independent periods. The results are compared with those obtained from using sub-groups of randomly selected catchments. The results have also been compared against classical regionalisation based on spatial proximity, where all the 196 catchments are calibrated individually and the calibrated parameter set from the geographically closest catchment is used to simulate streamflow for 'ungauged' catchments.

The regional calibration and verification results for sub-grouping based on 'fPAR' provided very little improvement over the experiments where the catchments were sub-grouped randomly into three groups. This is an interesting result as we were expecting to see some major improvements when sub-grouping based on vegetation cover as Vaze et al. (2011a) have shown that incorporating vegetation cover in regional calibration can provide improved performance in both calibration and verification. The results here might be affected by the quality of input satellite data, using a single averaged value of fPAR for the entire period, the number of sub-groups used in this study, the insensitivity of hydrological model used here to vegetation cover or due to the fact that PPAR is not really the salient catchment descriptor for catchment runoff.

The results from this study suggest that the sub-grouping based on aridity index and rainfall seasonality can improve the model performance over an independent period, whereas just randomly sub-grouping catchments into smaller groups provide little to no improvement over using all catchments together. The results also show that the regional calibration for catchment sub-groups based on 'Aridity' index and rainfall 'Seasonality' with three sets of calibrated parameter values (one calibrated parameter set for each sub-group) can provide comparable results to those from the classical spatial proximity regionalisation approach (with one set of calibrated parameter values for each catchment, a total of 196 sets of calibrated parameters.)

The results and conclusions here are based on experiments carried out using just one conceptual daily rainfall-runoff model (GR4J). Also, only one sub-grouping scheme which divides the catchments into three sub-groups has been investigated. The results may vary for other rainfall-runoff models and when different sub-grouping schemes are used. But the overall results from this study suggest that catchment physical and climatic characteristics-based sub-grouping has potential to improve the performance of regional calibration and regionalisation, and some catchment characteristics may be more informative for estimating runoff in a specified region than others.

\section{REFERENCES}

Bardossy, A. (2007). Calibration of hydrological model parameters for ungauged catchments. Hydrology and Earth System Science, 11, 703-710.

Beven, K., and Freer, J. (2001). Equifinality, data assimilation, and uncertainty estimation in mechanistic modelling of complex environmental systems using the GLUE methodology. Journal of Hydrology, 249, 11-29.

Bloschl, G. (2005). Rainfall-runoff modelling of ungauged catchments. in Encyclopedia of Hydrological Sciences, pp. 2061-2080, John Wiley, Chichester, U.K.

Donohue, R.J., Roderick, M.L. and McVicar, T.R. (2008). Deriving consistent long-term vegetation information from AVHRR reflectance data using a cover-triangle-based framework. Remote Sensing of Environment, 112 (6), pp. 2938-2949.

Duan, Q. Y., Gupta, V. K. and Sorooshian, S. (1993). Shuffled complex evolution approach for effective and efficient global minimization. J. Optmiz. Theory Appl. 76(3), 501-521.

Jeffrey, S.J., Carter, J.O., Moodie, K.M. and Beswick, A.R. (2001). Using spatial interpolation to construct a comprehensive archive of Australian climate data. Environmental Modelling and Software, Vol 16/4, pp 309-330.

Merz, R. and Bloschl, G. (2004). Regionalisation of catchment model parameters. J. Hydrol., 287, 95-123, doi:10.1016/j.jhydrol.2003.09.028.

Merz, R. and Bloschl, G. and Parajka, J. (2006). Regionalisation methods in rainfall-runoff modelling using large catchment samples. in Large Sample Basin Experiments for Hydrological Model Parameterisation: 
Wang et al., Catchment grouping and regional calibration for predictions in ungauged basins

Results of the Model Parameter Experiment-MOPEX, edited by V. Andreassian et al., IAHS Publ., 307, $117-125$

Nash, J.E. and Sutcliffe, J. V. (1970). River flow forecasting through conceptual models, I, A discussion of principles. J. Hydrol, 10, 282-290.

Oudin L., Andreassian V., Perrin C., Michel C. and Le Moine N. (2008). Spatial proximity, physical similarity, regression and ungauged catchments: a comparison of regionalization approaches based on 913 French catchments. Water Resources Research, 44(W03413).

Parajka, J., Bloschl, G. and Merz, R. (2007). Regional calibration of catchment models: Potential for ungauged catchments, Water Resour. Res., 43, W06406, doi:10.1029/2006WR005271.

Perrin, C., Michel, C. and Andreassian, V. (2003). Improvement of a parsimonious model for streamflow simulations. Journal of Hydrology, 279, 275-289.

Sivapalan, M., Takeuchi, K., Franks, S. W., Gupta, V. K., Karambiri, H., Lakshmi, V., Liang, X., McDonnell, J. J., Mendiondo, E. M., O'Connell, P. E., Oki, T., Pomeroy, J. W., Schertzer, D., Uhlenbrook, S. and Zehe, E. (2003). IAHS decade on Predictions in Ungauged Basins (PUB), 2003-2012: Shaping an exciting future for the hydrological sciences, Hydrological Sciences Journal-Journal Des Sciences Hydrologiques, 48, 857-880.

Vaze, J., Chiew, F. H. S., Perraud, JM., Viney, N., Post, D. A., Teng, J., Wang, B., Lerat, J. and Goswami, M. (2010). Rainfall-runoff modelling across southeast Australia: datasets, models and results. Australian Journal of Water Resources, Vol 14, No 2.

Vaze, J., Davidson, A., Teng, J. and Podger, G. (2011b). Impact of climate change on water availability in the Macquarie-Castlereagh river basin in Australia. Hydrological Processes, Vol 25, Issue 16, 2597-2612, DOI: $10.1002 /$ hyp.8030.

Vaze, J., Perraud, J-M., Teng, J., Chiew, F.H.S. and Wang, B. (2011a). Estimating regional model parameters using spatial land cover information - implications for predictions in ungauged basins. $19^{\text {th }}$ MODSIM Congress, Perth, Australia, 12-16 December 2011. http://mssanz.org.au/modsim11.

Vaze, J., Zhang, Y., Chiew, F.H.S., Wang, B. and Teng, J. (2013). Regional calibration against multiple data sources to predict streamflow. Climate and Land Surface Changes in HydrologyProceedings of H01, IAHS-IAPSO-IASPEI Assembly, Gothenburg, Sweden, July 2013 (IAHS Puble.359, 2013) 165-170.

Viney, N. R., Perraud, J-M., Vaze, J., Chiew, F.H.S., Post, D.A. and Yang, A. (2009). The usefulness of bias constraints in model calibration for regionalisation to ungauged catchments. 18th World IMACS / MODSIM Congress, Cairns, Australia 13-17 July 2009.

Vogel, R.M. (2005). Regional Calibration of Watershed Models, Chapter 3 in Watershed Models, V.P. Singh and D.F. Frevert editors, CRC Press, pp.47-71.

Zhang, Y.Q. and Chiew, F.H.S. (2009). Relative merits of different methods for runoff predictions in ungauged catchments. Water Resources Research, 45: W07412, doi:10.1029/2008wr007504. 